\title{
Liberdade em Bergson: espontaneidade, criação e auto-engendramento
}

Freedom in Bergson: Spontaneity, Creation and Self-engendering

\section{Maria Adriana Camargo Cappello Universidade Federal do Paraná [UFPR]}

\section{RESUMO}

O objetivo do artigo é examinar as noçóes de espontaneidade, criação e auto-engendramento na obra de Bergson, com ênfase na maneira como elas se articulam em $O s$ dados imediatos da consciência e $A$ evolução criadora, destacando as articulaçóes e diferenças entre as duas obras a esse respeito.

\section{PALAVRAS-CHAVE}

Espontaneidade; Criação; Auto-engendramento; Esquematismo; Imitação.

\section{ABSTRACT}

The aim of the article is to show how the notions of spontaneity, creation and selfengendering such as they occur in the $A n$ Essay on the Immediate Data of Consciousness and on Creative Evolution, paying attention to continuities and changes they go through from one work to the other.

\section{KEY WORDS}

Spontaneity; Creation;

Self-engendering; Schematism; Imitation. 
Para Bergson, "somos livres quando nossos atos emanam de nossa personalidade inteira, quando a exprimem" (Bergson, 2007, p. I29). Enquanto expressão da personalidade, portanto, o ato livre é, ainda que de um modo bastante próprio, "determinado"I pela personalidade que ele exterioriza no momento da ação. Pelo que, podemos dizer já de início, para Bergson a liberdade nada tem a ver com uma indiferença ou indeterminação do sujeito diante de várias possibilidades de açáo — o também chamado livre arbítrio ou "poder de opostos" — mas, ao contrário, como veremos, para ele liberdade é espontaneidade.

No entanto, se a caracterização da liberdade como expressão da personalidade impede sua identificação à indeterminação do livre arbítrio, por outro lado, sua caracterização como expressão da "personalidade inteira", ou seja, da personalidade considerada em seu constante processo de totalização, interdita as conclusões deterministas próprias à psicologia associacionista, a qual identifica, justamente, determinação à previsibilidade. De fato, para Bergson, o ato livre, enquanto expressão de uma consciência, é "determinado" pelo que a consciência é, ainda que não seja passível de ser previsto, e isto porque a consciência aqui considerada é a consciência em duração. E, conceber a consciência enquanto consciência em duração implica, justamente, afastar a possibilidade mesma que funda o determinismo associacionista, ou seja, afastar a concepção que espacializa a consciência. Consciência espacializada que passaria, entáo, a ser considerada como uma justaposição de estados psíquicos idênticos e distintos entre si, articuláveis do exterior, nos moldes de uma relação habitual e, por isso mesmo, previsíveis. Mas, justamente, considerar a consciência em duração é considerar, ao contrário, que seus estados se fundem uns nos outros, que seus estados são como um mesmo estado contínuo que se prolonga, cresce e se diferencia, nas palavras de Bergson, um estado que "infla continuamente com a duração que vai juntando", ou seja, é considerar a consciência como um estado

I Optamos, aqui, pelo uso do verbo "determinar", por ser este o termo usado no Ensaio, no contexto em questáo, como é possível observar no seguinte trecho: "Trata-se de uma psicologia grosseira, iludida pela linguagem, aquela que nos mostra a alma determinada [déterminée] por uma simpatia, por uma aversão ou pela raiva, como por forças que pesam sobre ela. Cada um desses sentimentos, uma vez que tenham atingido profundidade suficiente, representam a alma inteira, no sentido em que todo o conteúdo da alma se reflete em cada um deles. Dizer que a alma se determina [se détermine] sob a influência de qualquer um de seus sentimentos é, portanto, reconhecer que a alma se determina [se détermine] a si mesma" (Bergson, 2007, p. I24). No entanto, para indicar, a nosso ver, a mesma relação entre a totalidade de nossa consciência, presente e passada, e nossos atos, em Matéria e Memória Bergson substituirá o verbo "determinar" por "condicionar": "Nossa vida psicológica passada, inteira, condiciona [conditionne] nosso estado presente, sem determiná-lo de modo necessário." (Bergson, 1999, p. I62). Aparentemente Bergson quer evitar que se considere a "determinação", referida no Ensaio, como uma determinação "necessária", que denotaria uma relação estabelecida desde sempre, passível de ser prevista, enfim, uma relação na qual o tempo e sua eficácia, enquanto produçáo de novidade, não seria considerado.

2 Como podemos confirmar com algumas passagens do Ensaio, é esta concepção de livre arbítrio, enquanto poder de opostos, que Bergson critica juntamente com o próprio determinismo: "Ter consciência do livre arbítrio, diz Stuart Mill, significa ter consciência, antes de ter escolhido, de poder escolher de outro modo. É precisamente assim, com efeito, que os defensores da liberdade a entendem; de fato, afirmam que, quando realizamos uma ação de modo livre, qualquer outra açáo seria igualmente possível" (Bergson, 2007, p. I3I). "Ora, é fácil ver que essa concepção verdadeiramente mecanicista da liberdade chega, por uma lógica natural, ao mais inflexível determinismo" (ibid., p. I33). 
que não mais se associa a outro do exterior, mas se transforma em outro, do interior. Transformação que, justamente, não sendo mais da ordem do rearranjo de partes, é da ordem da produção do novo, da criação. Um estado absolutamente novo surge da atividade de fusão, uma ação absolutamente nova o expressa. Abandonado, assim, o pressuposto mesmo que funda o determinismo, ou seja, abandonada a concepção de consciência descontínua, regida pelo associacionismo, por uma concepção de consciência fundada na continuidade própria à duraçáo, o determinismo não mais se sustenta e a liberdade insere-se em um processo de criação.

Para além disso, entretanto, também o eu, caracterizado como este estado contínuo que dura e se exterioriza espontânea ou livremente no ato que o expressa, deve ser considerado, segundo Bergson, como aquele eu que se unifica na contínua variação de si a si, e que é, portanto, o sujeito de um auto-engendramento.

Se assim for, espontaneidade, criação e auto-engendramento parecem ser três aspectos-chave quando se quer compreender a reflexão bergsoniana sobre a consciência humana e a liberdade que a caracteriza. Vejamos, então, um pouco mais de perto, cada um desses aspectos.

\section{Consciência em duração}

Iniciemos com a relação acima apontada entre a espontaneidade da consciência e a imprevisibilidade dos atos que a expressam, ou seja, nos voltemos para o sentido mesmo do tipo de "determinaçáa" implicada no ato livre, considerando mais de perto o tipo de consciência que está na base da dissolução, por Bergson, do problema da liberdade ou seja, da dissoluçáo tanto do livre arbítrio quanto do determinismo.

De fato, no capitulo três do Ensaio, o livre arbítrio aparece como uma concepção de liberdade tão passível de ser criticada quanto todas as formas de determinismo ali examinadas. É neste texto que Bergson nos apresenta sua concepção de liberdade como consequência das análises desenvolvidas no primeiro e segundo capítulos, nos quais a consciência nos é apresentada segundo a duração que a caracteriza. E é a esta liberdade, que então aparece como a expressão mesma da consciência em duração, que Bergson contrapóe, não apenas os vários tipos de determinismo, que ele apresenta e critica separadamente, mas também o livre arbítrio. Isto porque, tanto os determinismos, quanto a liberdade concebida como o poder do sim e do não, não levam em conta a temporalidade própria à consciência e a colocam como um ponto estanque, ou entre reais alternativas de escolha - livre arbítrio — , ou como simples elo de uma cadeia que tem sua determinação inscrita na própria ordem de sucessão.

Então, vejamos. O que justamente caracteriza o ato livre, e o tipo específico de determinação nele implicado, é o fato de ele ser resultado de uma consciência que é considerada como um contínuo em constante movimento de totalização. Determinação que se distingue, portanto, daquela de um ato que se seguisse de um estado de consciência quando esta mesma consciência fosse considerada como um conjunto de estados distintos e justapostos, à moda de partes extra partes.3

3 É importante, aqui, para bem compreender as novas concepçôes de determinação, de ato livre e, 
E este, justamente, o sentido da imagem da justaposição, ao qual nunca é demais se remeter, a saber, o da distinção própria aos objetos que, considerados segundo sua identidade e impenetrabilidade, são constituídos, segundo a própria constituição dos números, a partir do conceito de espaço.

Com efeito, Bergson só chega à caracterização da consciência, como duração, no Ensaio, após ter feito a crítica da consciência espacializada, ou seja, daquela consciência decomposta em estados distintos e justapostos. Estados que, entáo, só poderiam nos dar a multiplicidade proveniente de uma justaposiçáo — concepção associacionista da consciência própria ao determinismo - , ou nos remeter à unidade de uma consciência vazia, concebida como puro ato - o eu indeterminado do livre arbítrio. Espacialização da consciência a partir da qual, portanto, jamais poderíamos ter a experiência original da consciência ao mesmo tempo una e múltipla — ainda que de uma outra unidade e de uma outra multiplicidade que não a numérica —, que é ato indiscernível de seu conteúdo e cuja expressão livre não é, no entanto, nem indeterminada nem indiferente.

De fato, se a matemática é aplicável com sucesso ao universo dos objetos materiais, ou se os progressos da física-matemática são tão evidentes, é porque o mesmo esquema da espacialidade - aquele da justaposição de unidades com exterioridade recíproca subjaz tanto à enumeração quanto à objetivação.

Convergência entre a objetivação e a enumeração que se explicita, tanto no que diz respeito ao tipo de unidade - ou ao tipo de contínuo - , quanto ao tipo de multiplicidade próprios ao número e ao objeto - unidade e multiplicidade que, de resto, são os dois lados de uma mesma moeda. Com efeito, o que nos diz Bergson quando nos apresenta sua análise da unidade referida na definição do número como "síntese do uno e do múltiplo"? Justamente que as unidades que compóem um número têm uma aparência de irredutibilidade - ou de continuidade intrínseca - que se deve, no entanto, apenas e unicamente a uma atenção ou atividade do espírito que as mantêm assim como unidade (contínuo) indivisível passível de ser adicionada a outra unidade.

Atenção ou atividade do espírito que, no entanto, uma vez suspensa, resulta em uma dissolução dessas unidades em um mesmo contínuo o qual passa, então, a ser indefinidamente dividido em outras tantas partes ou unidades. De fato, quando conto até 3 , é preciso que as "partes" que eu acrescento umas às outras se mantenham enquanto tal — sejam unidades, meios, terços, quartos etc. Mas, uma vez concluída a soma, também é fato que as partes distintas e indivisíveis pelas quais o numero 3 foi composto perdem sua distinção passando a compor elas mesmas uma única e mesma unidade — justamente a do número 3 -, ou um mesmo contínuo passível agora de ser novamente dividido

de consciência, enfim, que Bergson está forjando, distingui-las da concepção de consciência, ato e determinação proveniente de uma objetivação, ou, nos termos de Bergson, de uma espacializaçáo indevida do real. É importante aqui, como de resto, em tudo mais, para Bergson, distinguir o âmbito da duração, da real sucessão ou mudança, e o âmbito do espaço, ou da justaposição. 
em uma infinidade de outras partes. ${ }^{4} \mathrm{E}$ isto porque o que caracteriza a quantidade, a própria progressão numérica, o número, enfim, é a possibilidade mesma de distinção não qualitativa que só pode se dar pela exterioridade recíproca, pelo lugar ocupado, que implica a noção de espaço. É assim que, ao contrário do que Kant afirmava, para Bergson, não é o tempo, mas o espaço a condição transcendental do número, o espaço, este "meio vazio homogêneo", esta concepção de continuidade que é o esquema mesmo da indefinida exteriorização de partes, ou indefinida divisibilidade.

Indefinida divisibilidade não à toa identificada por Bergson, na conclusão de sua análise do número, à divisibilidade do objeto, e que vem mesmo a caracterizar o objetivo por distinção ao subjetivo. E é à luz dessa indefinida divisibilidade que, com efeito, devemos interpretar aquelas palavras de Bergson que tanto estranhamento causaram: "chamamos [...] objetivo o que é conhecido de modo que uma multiplicidade sempre crescente de novas impressôes pode substituir a ideia que atualmente temos de algo. [...] Nada muda no aspecto total de um corpo, de qualquer modo que o pensamento o decomponha, porque estas diversas decomposições, assim como uma infinidade de outras, já estão visíveis na imagem, ainda que não realizadas [...]" (Bergson, 2007, p. 63). De fato, nossa percepção de um objeto é de mesma natureza de nossa percepção do número 3, na medida em que tanto podemos perceber o mesmo número 3 como uma adição de unidades, meios, terços, quartos etc. quanto podemos perceber, por exemplo, uma mesma cadeira ("nada muda no aspecto geral etc."), por seu acento, encosto e pernas, ou pelos indefinidos elementos que pudermos destacar destes três elementos inicialmente percebidos - toda a quantidade indefinível de "detalhes", se assim podemos dizer, que podemos destacar destes mesmos acento, encosto e pernas. Ambos, os números e os objetos, constituem contínuos passíveis de serem apreendidos enquanto multiplicidades distintas, na medida, justamente, em que podem ser percebidos por indefinidas novas partes pela indefinida divisão ou distinção por exteriorização recíproca que nelas po-

4 "Não nos enganemos, com efeito, quanto à descontinuidade do número. Não poderíamos negar que a formação ou construção de um número implica a descontinuidade. Em outros termos, como dizíamos acima, cada uma das unidades com as quais formo o número três parece constituir um indivisível enquanto opero sobre ela e passo sem transição da que precede a que se segue. Sendo assim, quer se construa um mesmo número com meios, quartos, ou com quaisquer outras unidades, estas unidades ainda constituiriam, na medida em que servem para formar o número, elementos provisoriamente indivisíveis, sendo sempre de modo brusco, por saltos, por assim dizer, que iremos de um a outro. E isto se explica porque, para obter o número, é forçoso fixar a atençáo subsequentemente a cada uma das unidades que o compóem. É assim que a indivisibilidade do ato, pelo qual concebemos qualquer uma delas, se traduz na forma de um ponto matemático que um intervalo de espaço vazio separa do próximo ponto. Mas, se uma série de pontos matemáticos escalonados no espaço vazio expressa suficientemente o processo pelo qual formamos a ideia de número, tais pontos matemáticos têm uma tendência a se desenvolverem em linhas à medida em que nossa atenção se desprende deles, como se procurassem reencontrarem-se uns aos outros. E, quando consideramos o número concluído, essa união é um fato: os pontos se transformaram em linhas, as divisóes se apagaram, o conjunto apresenta todas as características de um contínuo" (Bergson, 2007, p. 62). 
demos perceber. Mas trata-se apenas de novas partes, ou seja, de novas divisóes, de um único e mesmo contínuo, cujo aspecto geral em "nada muda".

Assim sendo, a noção de corpo, objeto, ou de partes da extensão, equivale à noção de número, uma vez que tais noçôes se resumem a uma justaposição de elementos, que, por sua vez, nascem do conceito de divisibilidade, impenetrabilidade, exterioridade recíproca que são os tantos nomes dados àquela propriedade constitutiva do conceito que chamamos de espaço.

Dito isto, vejamos, então, como a justaposição, própria aos objetos, determina a relação passível de ser estabelecida entre eles. Com efeito, justapor um objeto a outro implica, em $\mathrm{I}^{\circ}$ lugar, considerar cada um destes objetos segundo limites bem definidos e, em $2^{\circ}$ lugar, observar a manutenção destes limites nas várias possibilidades de associação que então se apresentarem. Dois objetos justapostos mantêm entre si exterioridade recíproca; um objeto não se "funde" no outro, não se altera com o outro, no máximo, se associa, ou é associado ao outro, do exterior, exerce uma atração ou repulsa sobre este outro objeto que se lhe mantém exterior.

Sendo assim, no universo dos objetos, distintos e justapostos não há alteração possível senão a da reconfiguração, não há verdadeira transformação, mas, apenas, mudança de lugar, de posição. "Um objeto material [...], nos diz Bergson, ou permanece aquilo que ele é, ou, caso mude sob a influência de uma causa exterior, representamo-nos esta mudança como um deslocamento de partes que, elas, não mudam." Pois, ele prossegue, "caso essas partes resolvam mudar, nós as fragmentaríamos por sua vez" só nos detendo "frente ao imutável".

No que nos interessa aqui, disto se seguem ao menos duas coisas.

Primeiro, uma vez que toda mudança se reduz à mudança de posição, e uma vez que aquilo que mudou de posição sempre pode voltar a assumir a posição anterior, segue-se que todas as mudanças que atingem um grupo de objetos no espaço são reversiveis, o que equivale a dizer, para Bergson, "que um estado do grupo poderá se repetir quantas vezes forem desejadas e que, por conseguinte, o grupo não envelhece. Não tem história” (Bergson, 2005, p. 9).

Segundo, uma vez que as alterações sofridas por este grupo não implicam alteração na natureza das partes, mas apenas da posição por ela ocupada, tais alteraçóes são, de direito, previsiveis. De fato, nos diz Bergson,

5 Divisóes que nada mais são, de resto, que a exterioridade recíproca ou impenetrabilidade, mais própria ao conceito mesmo de número e de objeto possibilitado pelo conceito de espaço, do que da matéria considerada em sua realidade concreta. Com efeito, nos lembra Bergson, a impossibilidade de dois corpos ocuparem o mesmo lugar no espaço já está implícita na própria ideia do número 2, uma vez que, na expressão "dois corpos" há a mesma ideia de duas posições no espaço presente na expressão "dois". Sendo assim, "se a impenetrabilidade passa quase sempre por uma qualidade da matéria, é porque consideramos a ideia do número como independente da ideia de espaço. Acreditamos então acrescentar algo à representação de dois ou vários objetos ao dizer que eles não podem ocupar o mesmo lugar: como se a representaçáo do número dois, mesmo abstrata, náo fosse, como já mostramos, a de duas posiçóes diferentes no espaço! Afirmar a impenetrabilidade da matéria, é, portanto, simplesmente, reconhecer a solidariedade das noçóes de número e de espaço, é anunciar uma propriedade do número, mais do que da matéria” (Bergson, 2007, p. 66). 
O que o grupo irá ser já está presente naquilo que ele é, com a condição de que incluamos naquilo que ele é todos os pontos do universo com os quais supomos que ele tenha relação. Uma inteligência sobre-humana calcularia, para todo e qualquer momento do tempo, a posiçáo de todo e qualquer ponto do sistema no espaço. E como não há nada, na forma do todo, além da disposição das partes, as formas futuras do sistema teoricamente podem ser vistas em sua configuração presente (Bergson, 2005, p. 9).

Em resumo, quando se trata de um grupo de objetos no espaço, "nele, nada se cria, a forma não mais do que a matéria" ou, o que para Bergson quer dizer o mesmo, "o tempo não o atinge" (ibid.).

Ora, este modelo da distinção e justaposição, próprio à multiplicidade numérica e aos objetos, é justamente o que deve ser suspenso quando se considera a consciência. Suspensão que, como nos mostra Bergson, no Ensaio, tem como consequência direta a experiência imediata da consciência em sua existência duracional e, portanto, enquanto multiplicidade qualitativa, enquanto um contínuo de estados fundidos uns nos outros em constante transformação, portanto, enquanto outra concepção de multiplicidade e de contínuo, ou, se quisermos, de um e de múltiplo.

Com efeito, é o que encontramos se considerarmos, agora, a caracterização do subjetivo apresentada por Bergson, paralelamente à caracterizaçáo de objetivo, na conclusão da análise do número de que tratamos acima. "Chamamos de subjetivo, nos diz então Bergson, aquilo que aparece inteira e adequadamente conhecido" e isto porque, justamente, quando se trata do subjetivo não encontramos o mesmo tipo de unidade - ou de contínuo - próprio ao número e ao objetivo, que pode se dar a conhecer por tantos modos diferentes quantas forem as partes nas quais pode ser dividida. Pelo contrário, a unidade subjetiva é aquela na qual, justamente por não haver justaposição e simultaneidade, cada nova "divisão", ou "emergência" de "partes" implica o surgimento, sucessivo, de uma unidade ou contínuo inteiramente novo. $\mathrm{O}$ que não quer dizer, por outro lado, que, aqui, cada unidade ou contínuo, não seja, em seu sentido próprio, também uma multiplicidade, mas multiplicidade virtual, ou de fusão, de modo que, como nos diz Bergson, "um sentimento complexo conterá um número bastante grande de elementos mais simples; mas, enquanto estes elementos não se destacarem com nitidez perfeita, não poderemos dizer que estão realizados e, desde que a consciência tenha deles percepção distinta, o estado psíquico que resulta de sua síntese terá por isso mesmo mudado" (Bergson, 2007, p. 62). Engendramento sucessivo do um, que é também múltiplo, na medida mesma em que o sentimento é um complexo com partes de tal modo indistintas que se transforma em outro complexo na medida mesma de qualquer distinção efetiva de partes. Um e múltiplo subjetivos que são a própria subjetividade ou consciência em duração que se quer dar a perceber no Ensaio.

Vejamos, ainda, como essa consciência duracional aparece na análise dos sentimentos profundos que nos é apresentada por Bergson no primeiro capítulo do livro. Apesar de, ali, o contexto ser outro, a saber, o da crítica à intensidade dos estados da consciência, a análise nos serve justamente porque, ao propor uma nova consideração de intensi- 
dade, revela-se para nós o que Bergson tem em mente quando considera a consciência segundo o modelo da fusáo — único pelo qual se pode compreender o contínuo qualitativo (ou a multiplicidade qualitativa) — por oposição ao modelo da justaposição - próprio ao contínuo quantitativo (ou à multiplicidade quantitativa). De fato, ao criticar a consideraçáo de nossos estados de consciência segundo a quantidade, ou seja, segundo nossa crença de que tais estados podem crescer ou diminuir pela adição ou subtração de partes, o que Bergson está denunciando, aqui também, é este prejuízo espacializante que justamente nos faz considerar cada estado de consciência como passível de ser caracterizado por uma quantidade $\mathrm{x}$ de uma de determinada qualidade cujas unidades se caracterizariam, novamente, pela identidade e pela impenetrabilidade, sendo "invioláveis", portanto, em relação aos demais estados qualitativos da consciência. Tais estados de consciência poderiam, entáo, crescer ou diminuir pelo acréscimo ou subtração de "unidades" da qualidade que o caracterizaria, mas nunca se diferenciar qualitativamente de si mesmos. Ao criticar o prejuízo espacializante desta interpretação, Bergson propóe que as alteraçóes de intensidade de nossos "estados" de consciência devam, antes, ser consideradas como a alteração qualitativa, mais ou menos profunda, da totalidade da consciência — ou da consciência em seu contínuo movimento de totalização por um de seus estados. Em outras palavras, segundo o modelo da fusão, a intensidade de um estado de consciência seria "experimentado" justamente pela capacidade de uma sensação, sentimento, ideia... alterar qualitativamente a consciência como um todo, ao mesmo tempo em que se altera a si mesmo, fazendo surgir um "novo" estado, uma nova qualidade. Entre os exemplos apresentados, vejamos o que Bergson nos diz sobre o sentimento de uma paixão profunda:

Por exemplo, um desejo vago que se transforma em uma paixão profunda. Vereis que a fraca intensidade desse desejo consistia, de início, no fato de ele lhe parecer isolado e como que estranho a todo o resto de sua vida interior. Mas pouco a pouco ele penetrou um maior número de elementos psíquicos, tingindo-os, por assim dizer, com sua própria cor; e eis que seu ponto de vista sobre o conjunto das coisas parece agora ter mudado. Não é verdade que, uma vez contraída uma paixão profunda, vos apercebeis que os mesmos objetos náo produzem mais a mesma impressão? [...] É que, quanto mais descemos nas profundezas da consciência, menos temos o direito de tratar os fatos psicológicos como coisas que se justapóem. Quando dizemos que um objeto ocupa um grande espaço na alma, ou mesmo que ele a ocupa inteira, devemos entender por isso apenas que sua imagem modificou a nuance de mil percepçôes ou lembranças, e que nesse sentido ela os penetra, sem, no entanto, nelas se fazer ver (Bergson, 2007, p. 6).

Sendo assim, quanto mais profundamente assimilamos aquilo que vivemos ao já vivido, mais essa vivência matiza e se matiza pela nossa personalidade — "cada um de nós, diz Bergson, tem sua forma de amar e de odiar, e esse amor, esse ódio, refletem a personalidade inteira" - e, nesse mesmo sentido, quanto mais o ato for "determinado" por este estado profundo, tanto mais será “determinado" pela alma inteira, mais será sua própria expressão, mais será livre: 
Cada um desses sentimentos, desde que alcancem uma determinada profundidade, representam a alma inteira, no sentido em que todo o conteúdo da alma se reflete em cada um deles. Dizer que a alma se determina sob a influência de qualquer um desses sentimentos é reconhecer que ela se determina a si mesma. [...] E a manifestação exterior desse estado interno será precisamente o que chamamos de liberdade, uma vez que somente o eu será seu autor, pois que essa manifestação expressará o eu inteiro. [...] É da alma inteira, com efeito, que emana a decisão livre; e o ato será tanto mais livre quanto mais a série dinâmica com a qual ele se relaciona se identificar com o eu fundamental (Bergson, 2007, p. I23).

Voltemos, assim, à nossa questão. De que modo, caracterizados como expressão de um eu que dura, "determinados" por esse eu que eles expressam, os atos livres não implicam previsibilidade e, tampouco, indeterminação ou indiferença, mas, ao contrário, novidade e criação? Justamente porque o eu que dura, que se constitui segundo o modelo da fusão acima descrito, é a condensação de um passado único que se conserva e cresce, que "amadurece", ao assimilar de modo próprio a novidade de cada momento. O eu que dura é uma história individual em constante progresso. E é na medida mesma em que cada momento que se acrescenta ao passado o altera, e não apenas a ele se articula ou se justapóe, justamente porque há passagem real do tempo, não há repetição nessa história individual que então se constitui, não há repetição de causas ou motivos que se refletiria na repetição de efeitos previsíveis, "há criação contínua de imprevisível novidade".

\section{Ato livre, "momento original de uma história não menos original"}

Vejamos, então, de que modo Bergson constrói essa concepção do ato livre como a expressão dessa história única da consciência humana enquanto existência em duração.

É no capitulo três do Ensaio que Bergson nos apresenta sua concepção de liberdade como consequência das análises desenvolvidas no primeiro e segundo capítulos, nos quais a consciência é apresentada segundo seu traço essencial, a duração. E é a esta liberdade, que então aparece como a expressão mesma da consciência em duração, que Bergson contrapóe, não apenas os vários tipos de determinismo, que ele apresenta e critica separadamente, mas também o livre arbítrio. Isto porque, justamente, tanto os determinismos, quanto a liberdade concebida como o poder do sim e do não, não levam em conta a temporalidade da consciência e a colocam como um ponto estanque, ou entre reais alternativas de escolha - livre arbítrio —, ou como simples elo de uma cadeia que tem sua determinação inscrita na própria ordem de sucessão.

No entanto, antes de fazer a crítica ao determinismo associacionista, Bergson faz a crítica ao livre arbítrio, remetendo-se à oposição, de resto, menos profunda do que comumente se supóe, entre os defensores do livre arbítrio e os deterministas, a partir do diagnóstico proposto, não por acaso, por um filósofo empirista como Stuart Mill:

'Ter consciência do livre arbítrio, diz Stuart Mill, significa ter consciência, antes de ter escolhido, de poder ter escolhido de outro modo.' [...] Eles [os defensores do livre arbítrio] invocam a esse respeito o testemunho da consciência, que nos 
faz apreender, além do próprio ato, o poder de optar pelo partido contrário. Inversamente, o determinismo pretende que, tendo sido dados certos antecedentes, apenas uma ação resultante é possível: 'Quando supomos, continua Stuart Mill, que teríamos agido de outro modo, supomos sempre uma diferença nos antecedentes. Fingimos saber algo que não sabíamos, ou não saber algo que sabíamos, etc.' E, fiel a seu princípio, o filósofo inglês define como o papel da consciência nos esclarecer sobre o que é, não sobre o que poderia ser. [...]. Mas, ao lado dessa questão de ordem psicológica, há uma outra, de natureza mais metafísica, que tanto os deterministas quanto seus adversários resolvem a priori em sentido opostos. Com efeito, a argumentação dos primeiros implica que, dados certos antecedentes, um único ato é possível; os defensores do livre arbítrio supóem, ao contrário, que a mesma série pode resultar em vários atos diferentes, todos igualmente possíveis. É sobre essa questão da igual possibilidade de duas açôes ou de duas voliçốes contrárias que nos deteremos inicialmente, talvez assim recolhamos algumas indicaçóes sobre a natureza da operação pela qual a vontade escolhe (Bergson, 2007, p. I3I).

A resposta de Bergson à hipótese dos defensores do livre arbítrio, da oscilação entre duas possibilidades contrárias se dá, como não poderia deixar de ser, pela reafirmação do dinamismo do próprio processo, que teria sido esquecido por sua representação espacial. Trata-se, portanto, de denunciar a ilusão da fixação do eu diante de possibilidades de ação, $\mathrm{x}$ e $\mathrm{Y}$, que se colocariam diante dele; quando o que acontece é um processo dinâmico, o eu se transformando na medida mesma da sucessão de seus estados que só posteriormente serão colocados em oposição estrita, até que a ação se depreenda desse progresso como o "fruto maduro de uma árvore".

Consideremos a representação esquemática, apresentada por Bergson, de um processo decisório, no qual uma linha, que represente os sucessivos estados do eu, se iniciasse em M e prosseguisse até $\mathrm{O}$, ponto em que ela se bifurcaria em duas direçóes opostas, Ox e oY que se resolveriam em duas açôes opostas, $\mathrm{X}$ ou $\mathrm{Y}$. É neste ponto o que o defensor do livre arbítrio coloca o eu livre, que delibera entre dois opostos antes de agir. E, nesse ponto, em que o eu se mantém fixo, ele se isola, se destaca, tanto de seus estados passados, ou seja, de todos os motivos que o levaram até ali e que o levariam a optar por uma ou outra entre duas açóes opostas, quanto dessas mesmas açóes futuras, que aparecem diante dele como duas possibilidades igualmente realizáveis, "obtemos um eu indiferentemente ativo que hesita entre duas partes inertes e como que solidificadas" (Bergson, 2007, p. I33). E parece, portanto, ser no mesmo processo em que os estados do eu, condiçóes passadas e projeçôes de ações, se distinguem como coisas, que o próprio eu se distingue de seus estados e paira sobre tudo deliberando à distância. No entanto, a náo ser que queiramos sustentar uma tal concepção de absoluta distinção entre o eu e seus estados,

Uma vez que concordamos em localizar no ponto o a dupla atividade do eu [sua hesitação entre dois opostos], não há razão para destacar esta atividade do ato pelo qual ela se realizará, e que faz corpo com ela. E se a experiência mostra que decidimos por $\mathrm{x}$, não é uma atividade indiferente que devemos colocar no ponto o, mas antes uma atividade anteriormente dirigida para o ponto ox, 
a despeito da aparente hesitação. [...] Mas se o eu, ao chegar no ponto o, já está determinado em um sentido, o outro caminho pode continuar aberto, ele não poderá ser seguido. E o mesmo simbolismo grosseiro sobre o qual pretendíamos fundar a contingência da ação realizada acaba, por um prolongamento natural, a estabelecer uma absoluta necessidade (ibid., p. I34).

Antes, portanto, de problematizar a posição defendida pelo determinismo, interessa a Bergson chamar a atenção para a impossibilidade de manter a concepção clássica de livre arbítrio, ou liberdade de indiferença, pela qual o eu teria o poder de decidir entre duas possibilidades contrárias de ação. De fato, Bergson argumentará no sentido de defender que o livre arbítrio redunda inexoravelmente em determinismo ${ }^{6}$, de resto, de acordo com o próprio diagnóstico apresentado acima por Stuart Mill. Pois, o que é pressuposto quando defendemos este poder de escolha entre dois opostos? Justamente que o eu se paralise em um ponto fixo do qual ele deliberará sobre as duas possibilidades, também elas estanques. É deste modo, por exemplo, que Descartes afirmava que quando nossa vontade não era dirigida pelo entendimento ela se encontrava em situação de total indiferença, podendo nos levar a agir tanto em um sentido quanto em outro. $\mathrm{E}$, que, ainda que fosse natural a nossa vontade, pender fortemente para as verdades que o entendimento lhe apresentasse, o poder de agir na direção contrária, contra a própria razão, permaneceria.7 No entanto, dirá o determinista, se acabamos por nos decidir por um dos opostos é justamente porque algum dos motivos em questão assim o determinou, seja a evidência da verdade apresentada por um entendimento esclarecido, seja esta ou aquela paixão. Neste sentido, deterministas e defensores do livre arbítrio estariam em pé de igualdade, apenas os primeiros teriam levado em consideração todas as condições anteriores, enquanto os demais afetariam esquecer, em nome de uma possibilidade estritamente lógica, que qualquer que seja a ação realizada — trair a confiança de um amigo, ou, seu oposto lógico, não trair a confiança de um amigo — esta teria sido determinada pelo peso das condiçóes antecedentes.

Neste contexto, de resto, como diagnostica o próprio Bergson,

Os defensores e adversários da liberdade estáo de acordo, ao fazer preceder a ação de uma espécie de oscilação mecânica entre dois pontos X e Y. Se escolher X, os primeiros me dirão: você hesitou, deliberou, portanto, y era possível. Os outros responderão: você escolheu $\mathrm{x}$, portanto você tinha alguma razão para fazê-lo, e quando declara y igualmente possível, esquece essa razão; deixa de lado uma das condiçóes do problema (Bergson, 2007, p. 135).

Feita a crítica ao livre arbítrio, recaímos, então, num estrito determinismo? Bergson concorda com os deterministas em que não há ação destacada da massa de

6 "Ora, é fácil ver que esta concepção verdadeiramente mecanicista da liberdade redunda, por uma lógica natural, no mais inflexível determinismo" (Bergson, 2007, p. 133).

7 Cf. "Lettre à Mesland, 9 de fevereiro de I645". In: Descartes. Euvres et Lettres. Paris: Gallimard, 2008, pp. II77-II78. 
estados que constituem o eu e que seja, portanto, fruto de uma decisão indiferente. E, nesse sentido, Bergson concorda com os deterministas em que toda ação - parte integrante do eu, assim como seus demais estados, e em estreita relaçáo com eles encontra nos estados que constituem o eu sua explicação, na medida em que deles decorrem. Tudo se joga, no entanto, no diferente sentido dado, pelos deterministas e por Bergson, à relação, existente tanto entre os estados que compóem o eu, quanto entre eles e a ação que deles decorre.

Para os deterministas, essa relaçáo se resolve no sentido de uma determinação passível de se repetir e, portanto, de ser prevista. Pois, se minhas açôes decorrem das condiçôes anteriores às quais estão estreitamente ligadas, basta que estas condiçôes se apresentem novamente, e que eu tenha conhecimento de todas elas, para prever adequadamente a ação que se seguirá.

Ocorre que, como nota Bergson, em I l lugar, este tipo de relação entre uma ação e seus antecedentes é sempre estabelecida posteriormente à própria ação. De fato, é apenas uma vez a ação realizada que destacamos em nossos estados anteriores aqueles que detectamos como seus motivos. No entanto, estes motivos que se encontram em meio a outros que consideramos seus opostos e que, mesmo, alinhamos em uma sequência de tendência oposta, só ganham valor de determinação porque já sabemos que ação foi realizada.

É assim que, mais uma vez, a posição a ser criticada, agora a dos empiristas, o será levando em conta a temporalidade. De fato, tanto os empiristas quanto os defensores do livre arbítrio constroem suas hipóteses sobre nossas açôes voluntárias colocando-se sempre depois da ação realizada, tomando, portanto, como paradigma de suas teses, a representação destas açóes no espaço. Os primeiros valoram os estados anteriores que mantêm relações mais estreitas com o estado imediatamente anterior à ação, como as de contiguidade ou semelhança, enquanto os outros constroem a possibilidade da ação oposta àquela realizada a partir de um movimento retrógrado de fixaçáo do eu que delibera em um ponto arbitrariamente definido em sua trajetória passada. Uns e outros, portanto, recortam, no passado, estados determinantes, trajetórias opostas, pontos fixos de deliberação. Mas, do ponto de vista da temporalidade, para o qual Bergson nos chama a atenção,

Não há precisamente dois estados contrários, mas uma multiplicidade de estados sucessivos e diferentes no interior dos quais destaco, por um esforço de imaginação, duas direções opostas. [...] não há duas direçōes, mas um eu que vive e se desenvolve por meio de suas próprias hesitaçóes, até que a ação livre se desprenda como um fruto maduro (Bergson, 2005, p. 4).

É assim que, nem é fidedigna a descrição de nossas ações voluntárias, como aquelas provenientes de um eu que deliberaria sobre motivos opostos, de um ponto de observação exterior, no qual permanece indiferente e, a partir do qual, poderia seguir em uma ou outra direção, nem aquela que desconsidera essa mesma oposição, retraçando, a partir da ação atual, a série de motivos da qual ela inexoravelmente teria resultado. 
A ação, se levarmos em consideração o dinamismo próprio aos estados que constituem o eu, se segue como um desenvolvimento natural da fusão de todos os estados, de suas propensôes, deliberações, hesitaçóes, enfim, a ação é livre quando é a expressão mesma deste todo em constante fusão.

Assim nossa personalidade viceja, cresce, amadurece incessantemente. Cada um de seus momentos é algo novo que se acrescenta àquilo que havia antes. Podemos ir mais longe: não se trata apenas de algo novo, mas de algo imprevisivel. Sem dúvida, meu estado atual explica-se por aquilo que estava em mim e por aquilo que agia sobre mim há pouco. Ao analisá-lo, não encontraria outros elementos. Mas uma inteligência, mesmo sobre-humana, não poderia ter previsto a forma simples, indivisível, que é conferida a esses elementos, inteiramente abstratos, por sua organizaçáo concreta. Pois prever consiste em projetar no porvir o que vivemos no passado, ou em se representar para uma próxima ocasiấo uma nova junção, em outra ordem, de elementos já percebidos. Mas aquilo que nunca foi percebido e que ao mesmo tempo é simples será necessariamente imprevisível. Ora, tal é o caso de cada um de nossos estados, considerado como um momento de uma história que se desenrola: é simples e não pode já ter sido percebido, uma vez que concentra em sua indivisibilidade todo o percebido e, além disso, aquilo que o presente lhe acrescenta. É um momento original de uma história não menos original (Bergson, 2005, p. 6).

Pensado enquanto o momento original, de uma história não menos original, o ato livre guarda com a consciência a mesma relação, difícil de aprender e pela qual Bergson procura nos dar a própria duração, entre um movimento de totalização constante - criador, porque prenhe de virtualidades - e suas atualizaçóes. Pois, ainda que estas atualizaçóes sejam as atualizaçóes daquilo que o movimento traz em si enquanto virtualidade, tais atualizaçôes são absolutamente imprevisíveis.

\section{Liberdade e auto-engendramento da consciência}

Dito isto, é preciso considerar que, se a liberdade é espontaneidade, ou seja, expressão da própria consciência, na medida em que esta consciência assimila profundamente a novidade de cada momento vivido, gerando, ela também, a novidade - o que se opóe a uma assimilaçáo apenas superficial que acabaria por constituir uma cadeia de motivos ou de causas parciais, exteriores e, no limite, inconscientes, de açóes previsíveis - , esta liberdade, como espontaneidade implica um auto-engendramento. Não é à toa que Bergson completa a frase, que apresentei recortada acima, comparando o ato livre com a expressáo artística: "somos livres quando nossos atos emanam de nossa personalidade inteira, quando a exprimem, quando têm com ela esta indefinivel semelhança que por vezes encontramos entre a obra e o artista". Comparação apresentada uma primeira vez no Ensaio e que, ao ser retomada em Evolução Criadora, analisa a unidade do ato livre, enquanto auto-engendramento da pessoa e, justamente, também em suas outras duas características fundamentais: espontaneidade e criação. 
O retrato acabado explica-se pela fisionomia do modelo, pela natureza do artista, pelas cores esparsas na paleta; mas, mesmo com o conhecimento daquilo que o explica, ninguém, nem mesmo o artista, poderia ter previsto exatamente o que seria o retrato, pois predizê-lo teria sido produzi-lo antes que fosse produzido, hipótese absurda que se destrói a si mesma. $\mathrm{O}$ mesmo vale para os momentos de nossa vida, dos quais somos os artífices. Cada um deles é uma espécie de criação. E, assim como o talento do pintor se forma ou se deforma, em todo caso se modifica, pela própria influência das obras que produz, assim também cada um de nossos estados, ao mesmo tempo que sai de nós, modifica nossa pessoa, sendo a forma nova que acabamos de nos dar. Tem-se portanto razáo em dizer que o que fazemos depende daquilo que somos; mas deve-se acrescentar que, em certa medida, somos o que fazemos e que criamos continuamente a nós mesmos (Bergson, 2005, p. 7).

Mas, ainda que caracterizada enquanto expressão imprevisível de uma personalidade inteira, a liberdade, para Bergson, não é absoluta, mas, antes, tendência; ela comporta graus. ${ }^{8}$ De fato, Bergson nos chama a constatar que nossos atos realmente livres são extremamente raros $^{9}$ e que nos mantemos, na maior parte das vezes, aquém de nossa liberdade, e que, agimos, cotidianamente, segundo a determinação previsível de um ato por uma parte ou uma sequência de partes distintas de nós mesmos, segundo, portanto, o determinismo. Somos, na maior parte das vezes, autômatos conscientes, e é providencial, para nossa sobrevivência, que assim o seja.

Examinemos, nesse sentido, outro exemplo apresentado por Bergson. Todas as manhãs, ao sermos acordados pelo som de nosso despertador, associamos imediatamente tal som à ideia de nos levantarmos e nos ocuparmos de nossos afazeres. Tais ideias se relacionam por contiguidade e nos determinam a agir. Poderíamos mesmo duvidar que assim agiríamos efetivamente se deixássemos tal impressão se fundir à massa confusa das impressóes que nos ocupam. ${ }^{10} \mathrm{O}$ mais frequente, portanto, é que uma ideia se associe a outra ideia e que a elas se siga um ato no qual nossa consciência não está implicada. É assim que se constroem os hábitos, cuja importância na manutenção da pessoa, tanto no âmbito individual, quanto social, Bergson nunca cansa de enfatizar. ${ }^{\text {II }}$

8 "Nesse sentido, a liberdade não apresenta o caráter absoluto que o espiritualismo lhe dá às vezes; ela comporta graus" (Bergson, 2007, p. I25).

9 "Assim entendidos, os atos livres são raros, mesmo da parte daqueles que têm o costume de se observar a si mesmos e de raciocinar sobre o que fazem" (ibid., p. I26).

Io Cf. ibid.

II Com efeito, é no hábito, mais especificamente, no hábito de contrair hábitos, que Bergson encontrará, a partir da análise feita Nas Duas Fontes..., o fundamento mesmo das sociedades, e, no imperativo de que haja hábitos, o da moral de uma sociedade fechada, voltada para a sua manutençáo, e a de seus membros, contra as demais sociedades. Ali, também, no âmbito do coletivo, oscilamos entre o mais baixo grau de liberdade, o de aderir a este ou outro hábito, tendo como pano de fundo, a necessidade mesma do hábito, e a verdadeira liberdade, aquela que, não se prendendo mais a este ou aquele objetivo, a manutenção desta ou daquela sociedade, é a expressão mesma de uma vontade que, ao se expressar, acaba rompendo qualquer barreira e se expandindo na direção da humanidade inteira. 
É assim que Bergson, ao afirmar a liberdade da consciência, acaba por abandonar uma caracterização identitária da consciência e, consequentemente, absoluta da liberdade, e por reconhecer que a consciência existe, ou desenvolve-se, segundo duas tendências; de um lado, aquela de sua própria constituição, pela qual suas ações são tanto mais livres quanto mais são a expressão da fusão da sucessão dos momentos vividos e, em sentido contrário, aquela de sua dissolução, tendência, justamente, da distinção de seus estados e de sua consequente associação do exterior, cujos atos — verdadeiros atos-reflexos são regidos por motivos impessoais ou pelo hábito. ${ }^{12}$

É certo que o ato livre deve ser buscado para além da indiferença e contra a determinação de nossas açóes por esta ou aquela impressão superficial que, em seu apartamento da massa que constitui nossa personalidade, é táo pouco nossa, prescinde tão pouco de nossa consciência, beira ao automatismo. E é certo também, como nos diz Bergson ainda no Ensaio, que o ato livre deve ser procurado naquelas ocasióes raras e solenes capazes de nos engajar em uma expressão totalizante, de nos engajar no sentido da concentração em nós mesmos, responsável pela continuidade que então se exteriorizará em ato, mas é certo também, como Bergson explorará com as novas perspectivas abertas em Evolução Criadora, que o ato livre nos engaja, não apenas no sentido da expressão atual do que somos, mas de própria gênese do que seremos, do que estamos em vias de ser, de nosso devir, pela tensão de nossa vontade, sentido, justamente, que se opóe àquele da dissolução ao qual tendemos pelo relaxamento dessa mesma vontade.

Quanto mais consciência tomamos de nosso progresso na pura duração, mais sentimos as diversas partes de nosso eu entrar umas nas outras e nossa personalidade inteira se concentrar em um ponto, ou melhor, em uma ponta, que se insere no futuro engendrando-o sem cessar. Nisso consiste a vida e as açóes livres. Ao contrário, deixemo-nos levar: no lugar de agir, sonhemos. Nosso eu se dispersa; nosso passado, que até aqui se concentrava sobre si mesmo no impulso indivisível que ele nos comunicava, se decompóe em mil e uma lembranças que se exteriorizam umas em relação às outras. Renunciam a se interpenetrar quanto mais se cristalizam. Nossa personalidade desce assim na direção do espaço. (Bergson, 2007b, p. 202)

Há aqui, portanto, de um modo muito mais enfático do que aquele apresentado no Ensaio, a remissão a um engajamento necessário para que nossa personalidade se constitua e para que seja livre, o que, no limite, parece ser uma e a mesma coisa. De fato, no Ensaio, Bergson já havia se referido a esse querer "raro" quando ele nos diz, ali, que "se somos livres todas as vezes em que desejamos entrar em nós mesmos, poucas vezes o queremos." (Id., 2007, p. I80) No entanto, parece ser apenas pela inserção desse querer

I2 De fato, se bem observarmos, "Veremos que a maior parte de nossas açóes cotidianas se realizam assim, e que graças à solidificaçâo, em nossa memória, de certas sensaçóes, certos sentimentos, certas ideias, as impressóes de fora provocam de nossa parte movimentos que, conscientes e mesmo inteligentes, se parecem, em vários aspectos, a atos reflexos. É a essas açóes bastante numerosas, mas em sua maior parte insignificantes, que a teoria associacionista se aplica" (Bergson, 2007, p. 127). 
individual de nossa consciência no próprio movimento criador daquilo que ali ele chama de Supra Consciência, que é princípio de tudo o que existe, e que se continua no movimento gerador da vida (no qual, finalmente, nossas consciências individuais são geradas) que esse querer poderá ganhar toda a sua dimensão.

Pois será ali, em Evolução Criadora, quando esta Supra Consciência e o elã da vida forem efetivamente considerados, que se explicitará a relação intrínseca entre este querer de uma consciência individual, a Supra Consciência e a própria Vida. Vida, na qual, de resto, ao ser justamente um tipo bastante específico de persistência do esforço de criação próprio à Supra Consciência passará a ser considerada, para além de um puro mecanicismo ou finalidade, como verdadeira criação contínua.

Quando recolocamos nosso ser em nosso querer, e nosso próprio querer no impulso que o prolonga, compreendemos, sentimos que a realidade é um crescimento perpétuo, uma criação que prossegue sem fim. Nossa vontade já faz esse milagre. Toda obra humana que contém uma parte de invenção, todo ato voluntário que contém uma parte de liberdade, todo movimento de um organismo que manifesta espontaneidade, traz algo de novo ao mundo. É verdade que se trata da criaçấo de formas. Como poderia ser outra coisa? Não somos a própria corrente vital; somos essa corrente já carregada de matéria, quer dizer, de partes congeladas de sua substância que ela arrasta ao longo de seu percurso. Na composição de uma obra genial, assim como em uma simples decisão livre, por mais que tencionemos no mais alto grau a mola de nossa atividade e criemos assim o que nenhuma junção pura e simples de materiais teria podido oferecer (que justaposição de curvas conhecidas equivaleria algum dia ao traço de lápis de um grande artista?), nem por isso deixa de haver aqui elementos que preexistem e sobrevivem à sua organização. (Bergson, 2007b, p. 240)

A consideração da liberdade das consciências individuais no âmbito trazido pela consideração da Supra Consciência, que é a liberdade mesma na medida em que é pura "exigência de criação" - e criação, tanto de formas de vida, de formas de consciências, quanto de matéria - demanda, certamente, que nos detenhamos na consideração dessa Supra Consciência e na dinâmica de seu movimento. Investigação que extrapola, em muito, o escopo da presente reflexáo. Fiquemos, por ora, portanto, com a consideração da liberdade humana segundo esse querer "entrar em si mesmo", esse deixar de agir automaticamente, esse deixar agir o eu inteiro em sua duração, pelo que, então, ser livre, durar e, mesmo, simplesmente ser, termos que agora se correspondem, surgirão como a expressão mesma de nossa pura espontaneidade.

\section{Referências bibliográficas}

Bergson, H. (I999). Matiére et Memoire. Paris: puf. (2007). Essai sur les données immédiates de la conscience. Paris: Puf. (2007b). L'évolution créatrice. Paris: PUF. (2005). A Evolução Criadora. Trad. de Bento Prado Neto. São Paulo: Martins Fontes. 